\title{
TEMPERATURE ESTIMATES OF THE PLANET MARS
}

\author{
By W. W. Coblentz
}

\section{ABSTRACT}

The present paper gives the results of an investigation of methods of estimating planetary temperatures, especially of Mars, from measurements obtained by newly designed radiometric instruments adapted to these problems. These temperature estimates are based upon radiometric measurements made at the Lowell Observatory, Flagstaff, Ariz., during 24 nights extending over a period of 10 weeks from July to September, 1924.

By means of a series of transmission screens of water, quartz, glass, and of fluorite the planetary radiation emanating from the irradiated surface of Mars was resolved into spectral components. These radiometric measurements were reduced to temperatures by four independent methods of analysis, giving concordant results and showing that the bright areas along the apparent center of the disk have a temperature of -10 to $+5^{\circ} \mathrm{C}$., while the contiguous dark areas have a temperature of 10 to $20^{\circ} \mathrm{C}$.

During the period covered by these observations the temperature of the north polar region, where winter prevailed, remained fairly constant at $-70^{\circ} \mathrm{C}$., while in the south polar region, where summer was advancing, the temperature increased to $10^{\circ} \mathrm{C}$., or perhaps even higher, at the Martian summer solstice.

The temperature of the east limb, or sunrise side, of the planet is lower than that of the west limb, being -45 and $0^{\circ}$ C., respectively, at opposition, August 21. The average temperature of the whole disk in the latter part of June was $-30^{\circ}$ C. The temperature of the night side of Mars probably drops below $-70^{\circ} \mathrm{C}$.

\section{CONTENTS}

I. Introduction

II. Methods of obtaining planetary temperatures from radiometric measurements _._._.

1. Planetary temperatures derived from the law of total radiation

2. Planetary temperatures derived from the law of spectral radiation.

3. Planetary temperatures derived from a comparison with the moon

4. Planetary temperatures inferred from comparisons with the earth

5. Comparison of temperature estimates.......... 385

III. Climatic conditions on Mars . .

1. Average temperature of the whole surface of Mars.........

2. Radiation from and temperatures of selected regions........

(a) Bright and dark equatorial regions.............

(b) East and west limbs

(c) North and south polar regions

3. Seasonal variation of temperatures on Mars........... 393

IV. Concluding remarks and summary ............... 395 


\section{INTRODUCTION}

During the summer of 1924 , through the courtesy of the Lowell Observatory (elevation 7,250 feet), Flagstaff, Ariz., the writer was kindly invited to continue his investigations of 1922 relating to instruments and methods of radiometry as applied to the measurement of planetary radiation and planetary temperature. C. O. Lampland again collaborated in the work, and it is proposed to publish the complete results and their astronomical significance in a joint paper on this subject.

The object of the present paper is to summarize the results of a study of methods of estimating planetary temperatures as deduced from the radiometric measurements on Mars and on the moon.

Mars approached closest to the earth (attained its greatest brightness, 100) August 21, 1924. Almost half a century must elapse before it will attain a similar brightness (98), and 15 years must elapse before it will attain a brightness of 90 . Hence, it is important to leave the present results in as complete and as accessible a form as possible for future reference.

The temperature which the surface of Mars attains when exposed to solar radiation is a much debated question. Some of the older calculations-for example, Poynting's-indicated a temperature much below $0^{\circ} \mathrm{C}$. More recently Lowell introduced factors previously neglected and calculated temperatures considerably above $0^{\circ} \mathrm{C}$. This is in agreement with the visual observations which have been in progress for years, showing a periodic waxing and waning of the polar caps (presumably of snow) and the disappearances of the white deposits of frost under a Martian noonday sun.

With such conflicting opinions, it seemed desirable to reduce the radiometric data by various methods and to have some one not connected with the work make some of the calculations. Fortunately this could be done without inconvenience to anyone, for the measurements of 1922 on Mars had already been worked out by Menzel by a method outlined by Russell.' The writer, therefore, submitted to Doctor Menzel a considerable portion of this season's observations for calculation by this method. The results, ${ }^{2}$ which will be published in a separate paper, are included in the present discussion of the subject.

It is relevant to point out that, while the observations were in progress, it was considered quite an accomplishment to establish temperature differences on the surface of the planet. Now that the measurements have been completed and there is time for considering

1 Menzel Astrophys Jour., 58, p. 65; 1923.

${ }^{2}$ See preliminary communications: Washington meeting Am. Astronom. Soc. January and Am. Phys. Soc. Apr. 24, 1925. 
their significance, the demand has arisen for a higher accuracy in the temperature estimates than the observations seem to warrant.

In this discussion it will be necessary frequently to qualify the temperature estimates by statements regarding the effect of the atmosphere of Mars. This may be confusing to the rea.der. It is therefore desirable to discuss this question.

First of all it is important to recall that it is a matter of conjecture as to the extent, the composition, and the amount of the atmosphere on Mars. It is, therefore, impossible to correct our radiometric measurements for the effect of the Martian atmosphere upon (the depletion of) the planetary radiation emanating from the solid surface of Mars, which radiation forms the basis of these temperature estimates.

The agreement seems to be quite general that there is but little water on Mars. What little there is would, no doubt to a large extent, be congealed at the poles. As the seasons vary, water vapor would be transferred from the hotter to the colder pole, with probably but little condensation along the equator.

During the winter season, which occurred on the north polar region of Mars during the opposition of 1924, the overlying atmosphere was probably quite free from ice spicules and mist, and hence the estimated temperature (of $-70^{\circ}$ C.) relates to the solid surface.

At the time when there was winter on the northern hemisphere of Mars there was summer on the southern hemisphere, and the south polar cap was receding, indicating that its temperature was probably up to $0^{\circ} \mathrm{C}$. But under these conditions there would be an overhanging mantle of water vapor, and, perhaps, ice spicules which would prevent the escape of planetary radiation from the solid surface. As a result the water-cell transmissions were high, indicating a temperature of $-60^{\circ} \mathrm{C}$. This difference between the observed temperature of $-60^{\circ} \mathrm{C}$. and the value of $0^{\circ} \mathrm{C}$., inferred from an interpretation of the visible phenomena (that is, diminishing ice cap), is not an inconsistency, but a remarkable verification of the presence of an atmosphere containing a mantle of water in the form of ice spicules, or mist, which prevents the escape of planetary radiation from the solid surface. Later in the season this radiometrically opaque canopy seemed to disappear and the water-cell transmissions decreased to a low value, indicating a temperature of $10^{\circ} \mathrm{C}$. or even higher.

When atmospheric conditions, whether mundane or Martian, are most steady (that is, when there is "good seeing"), it is most difficult to obtain uniform galvanometer readings. This seems to be owing to the small receiver used, which responds to the differences in temperature over the surface of Mars, and especially of the moon. When the seeing is poor, the planetary image is unsteady and the thermo- 
couple receiver integrates the radiation over a larger area. As a result the measurements are apparently more reliable, in the sense that the individual readings do not depart so far from the average. However, they do not refer to the isolated areas. Some of this effect is apparently due to atmospheric conditions on Mars.

The presence of clouds on Mars is a well-recognized phenomenon. Occasionally they are conspicuous because of their size, brightness, and unusual location; as, for example, the great white spot ${ }^{3}$ of July 9,1922 , which occurred in the Tropics and covered an area of about 300,000 square miles. On June 21, 1924, V. M. Slipher ${ }^{4}$ observed a conspicuous white cloud, 500 miles in length and 2,000 miles in width, which disappeared by June 24. On October 27 Van Biesbroeck ${ }^{5}$ observed a luminous extension at the terminator of Mars more than 1,000 miles in length, which appeared to be an extended high cloud or fog illuminated in the morning sky before the subadjacent territory was fully irradiated and disappeared under the heat of the sun as it moved into daylight.

In some cases these temporary markings appear to be clouds of dust ${ }^{6}$ instead of water vapor, and at times the surface of the planet seems veiled as if the atmosphere of Mars were hazy. ${ }^{7}$

The occurrence of frost deposits on Mars is also recognized. In a paper on the presence of autumnal frosts in the south polar region of Mars, Lowell ${ }^{8}$ gives data showing that the morning frost lasted longer as the Martian season progressed later into the autumn, remaining in view till two hours after sunrise in Martian November and almost five hours after sunrise in December.

In view of the fact that our measurements show that the bright areas are at a lower temperature than the dark areas, it is interesting to record that Lowell observed that frosts appeared first on the bright regions, as they should if the areas are deserts. In the going of the snow and frost the dark areas reappeared the first, and in the coming of the frost the dark areas remained visible the longest, indicating the presence of vegetation. These conditions seem to require the presence of an atmosphere on Mars.

Because of the clearness of the markings when viewed on the edge of the planet, the belief has been held that the atmosphere of Mars is extremely tenuous and transparent. This interpretation is subject to qualification, for it is well known that on clear days one can see mountains 50 or more miles distant, which means vision through an air column several times the total mass viewed in the

3 E. C. Slipher, Publ. Astronom. Soc. Pacific, 34, p. 215; 1922. See also an earlier paper in Pop. Astron., 29, February, 1921.

${ }^{4}$ V. M. Slipher, Publ. Astronom. Pacific, 36, p. 219; 1924.

${ }^{5}$ V an Biesbroeck, Pop. Astron., 32, p. 589; 1924.

${ }^{6}$ Lowell, Bull., Lowell Obs., No. 1; 1903.

7 Hamilton, Lowell Obs., Bull., No. 82; 1918.

8 Lowell, Bull., Lowell Obs., No. 71; 1911. 
vertical direction; but vision in the vertical direction is affected by inhomogeneity in the water content of the atmosphere.

The recent photographs of Mars, obtained by Wright, ${ }^{9}$ show that the atmosphere extends, perhaps, 100 miles above the surface of the planet. Under the earth's gravitational force this would be compressed to about 45 miles. The effective thickness of the earth's atmosphere is estimated to be about 50 miles. On this basis it appears that the amount of atmosphere per unit surface area on Mars is quite appreciable. But with much less water on Mars, and the most of this congealed in the polar regions, it is evident that its distribution in the atmosphere can not obstruct vision as obtains on this earth. Nevertheless, the greater mass of water vapor or ice spicules in the polar regions would prevent the escape of planetary radiation, upon which our temperature estimates are based.

As already stated, it seemed quite an achievement to be able to differentiate between the temperature conditions of the bright and the dark regions, the polar caps, etc., and it was tacitly assumed that owing to the presence of the Martian atmosphere the temperatures of the east and west limbs of the planet are higher than the observed values.

Until we obtain data on the effect of the Martian atmosphere it does not seem desirable to attempt to specify more exact temperatures, especially at the poles and the limbs of the planet.

Mention has already been made of the waxing and waning of the polar caps which have the properties of snow, instead of being an atmospheric phenomenon. The photographic records of Slipher ${ }^{10}$ show that during the opposition of 1924 the behavior of the diminishing south polar cap was the same as in 1909 as to the rate of melting, the character of the dark border (interpreted as being water), the irregularities in its contour, the dark rifts (resulting probably from differences in elevation of the permanent surface), and the detached portions of the cap which have been left behind. during the recession.

On the other hand, both the visual and the photographic observations on the dark areas, to which frequent ref erence will be made in this paper, show that with advance in the Martian summer these markings increased in intensity until the summer solstice (October 5), after which they faded out again, thus repeating what has been observed during previous oppositions. All these phenomena indicate seasonal changes, while the variation in coloration of the dark markings indicate the presence of vegetation.

- Wright, Publ. Astronom. Soc., Pacific, 36, p. 239; 1924.

${ }^{10}$ E C. Slipher, Pop. Astron., 36, p. 255; 1924. 
In another paper ${ }^{11}$ it is shown that the high temperatures observed on these dark areas can be accounted for by the presence of tuftforming grasses such as grow on our high prairies, the tussock grasses of Peru and Patagonia, and especially the mosses and lichens which grow in the arctic regions. Data are cited showing that temperatures as high as $30^{\circ} \mathrm{C}$. have been observed in the mosses of the dry tundras of Siberia, whereas only a few centimeters beneath the ground was frozen. This is owing to the fact that the upper surface of tuftforming vegetation is a good absorber of solar radiation, while the underlying material is a poor conductor of heat. As a consequence, the upper surface, which is the region upon which the radiometric measurements are made, rises to a higher temperature than that of a similarly absorbing surface of rock or bare soil. The assumption of the presence of this form of vegetation is in harmony with visual observations and with the small temperature rise that would be expected because of the low insolation on Mars.

\section{METHODS OF OBTAINING PLANETARY TEMPERATURES FROM RADIOMETRIC MEASUREMENTS}

The instruments used in this investigation consisted of an ironclad Thomson galvanometer and vacuum thermocouples of bismuth and platinum described in previous publications. ${ }^{12}$ The window of the vacuum thermocouple container was of rock salt. ${ }^{13}$ By means of screens of water, quartz, glass, and flourite the radiation from the planet was separated into spectral components of wave lengths 0.3 to $1.4 \mu, 1.4$ to $4.1 \mu, 4.1$ to $8 \mu, 8$ to $12.5 \mu$, and 12.5 to $15 \mu$. In the present paper frequent reference will be made to the spectral component of 0.3 to $1.4 \mu$, which is transmitted by the water cell, and the ratio of the spectral components $\mathrm{A}: \mathrm{B}$ of wave lengths 8 to $12.5 \mu$ and 12.5 to $15 \mu$ obtained by elimination with the screens of glass and fluorite.

The measurements on the small isolated regions of Mars were made with a thermocouple receiver $0.23 \mathrm{~mm}$ in diameter, described in the preliminary measurements of planetary radiation. ${ }^{1 \pm}$ For obtaining the integrated temperature of the whole disk a thermocouple, having receivers $0.6 \mathrm{~mm}$ in diameter, was used to intercept the image of the whole disk of Mars.

These instruments were used in connection with the 40-inch reflector of the Lowell Observatory. Two focal lengths were used-18.4 and 53.3 feet, respectively. At the 53.3 -foot focus the image of the disk of Mars at opposition was $2 \mathrm{~mm}$ in diameter. Under these

11 Coblentz, Pop. Astron., 33, p. 310; 1925.

12 B. S. Sei. Papers Nos. 244, 282, 438, and 460

13 B. S. Sci. Papers, 17, p 725; 1921 (No. 438).

14 B. S. Sci. Papers, 18, p. 535; 1922 (No. 460). 
conditions the thermocouple receiver intercepted about one-eighth of the diameter of the disk image of Mars. This is a much greater resolution than has heretofore been attempted, and it has disclosed temperature conditions hitherto unobserved and perhaps unsuspected.

The radiometric observations upon which the various temperature calculations are based are given in Tables 1,2, and 3. Detailed information pertaining to these data are given in the complete paper which is to be published on this subject.

\section{PLANETARY TEMPERATURES DERIVED FROM THE LAW OF TOTAL RADIATION}

Using these water-cell transmissions it is possible to calcuiate the temperature of the planet by a method, the theory of which was outlined by Russell and the data worked out by Menzel. ${ }^{15}$ By this method the temperatures are derived from the fourth-power law of total radiation. All the factors, such as the per cent transmission through the water cell, the spectral transmission factors of the atmosphere, etc., enter as the fourth root in the equation, and hence the errors of observation are minimized in the calculated temperatures.

In this calculation the solar constant is taken as $1.932 \mathrm{~g}$ cal. $\mathrm{cm}^{-2}$ per min., and the Stefan-Boltzmann constant as $5.72 \times 10^{-12}$ watts or $8.21 \times 10^{-11} \mathrm{~g}$ cal. $\mathrm{cm}^{-2}$ per min. Numerous other factors, including the transmission of the atmosphere, are also considered. An uncertain factor which enters this method of calculation is the albedo of the isolated areas upon which the observations were made.

The water-cell transmissions of the radiation from Mars, observed on June 15 and 18, 1922, were worked out by this methr,d. The data which were obtained by using a receiver intercepuing about 0.4 the diameter of the planetary image gave a temperature of $-5^{\circ}$ C., while similar data obtained with a receiver 0.55 the diameter of the planetary disk gave a lower value, $-9^{\circ} \mathrm{C}$. From this year's measurements, which show a rapid decrease in temperature from the Equator to the poles and to the limbs, it is evident that these temperatures should be corrected for latitude (that is to say, the overhanging mantle of water vapor, ice spicules, or whaterer may be the cause of this rapid change in temperature). This correction would raise the estimated temperature of the equatorial region to $5^{\circ} \mathrm{C}$., or perhaps even higher.

Applying this method of calculation to this year's observations, ${ }^{16}$ the black body temperatures of the apparent center of the disk ranged from $-5^{\circ} \mathrm{C}$. on the bright areas to $22^{\circ} \mathrm{C}$. on the adjacent

\footnotetext{
${ }^{15}$ Menzel Astrophys. Jour., 58, p. 65; 1923.

${ }_{16}$ Menzel Coblentz, and Lampland, Washington Meeting of the Amer. Astronom. Soc., Jan, 1, and tho Amer. Phys. Soc., Apr. 24; 1925. $48620^{\circ}-25+-2$
} 
dark areas, the predominating values being 6 to $9^{\circ} \mathrm{C}$. After the Martian solstice (October 5) the temperature of the south polar region increased to $10^{\circ} \mathrm{C}$. The true temperatures would be about $10^{\circ}$ higher; that is, 15 to $20^{\circ} \mathrm{C}$.

The temperatures derived by this method of reducing the data are given in column 4 of Table 1 . They are in good agreement with those obtained by three other methods, all of which indicate conclusively that the equatorial temperature of Mars at perihelion was considerably above $0^{\circ} \mathrm{C}$. When one considers the difficulty in establishing - the temperature of a terrestrial object within $10^{\circ} \mathrm{C}$., it seems truly remarkable that these various methods appear to be so close in agreement in indicating that the temperature of Mars rises above $0^{\circ} \mathrm{C}$. This is an extremely important deduction, for the possibility of vegetable life on Mars is dependent partly upon the question of temperature conditions.

TABLE 1.-Mars

[Comparison of temperatures on the apparent center of the disk as obtained by various methods]

\begin{tabular}{|c|c|c|c|c|c|c|c|c|c|}
\hline \multirow{5}{*}{ Date } & \multirow{5}{*}{$\begin{array}{l}\text { Water- } \\
\text { cell } \\
\text { trans- } \\
\text { mission }\end{array}$} & \multirow{5}{*}{$\begin{array}{c}\text { Spectral } \\
\text { compo- } \\
\text { nents } \\
\mathrm{A}: \mathbf{B}\end{array}$} & \multicolumn{5}{|c|}{ Temperatures, ${ }^{\circ} \mathrm{C}$. , method } & \multirow{5}{*}{ Mean } & \multirow{5}{*}{ Region on Mars } \\
\hline & & & \multicolumn{2}{|c|}{ Black body } & \multicolumn{3}{|c|}{ Moon } & & \\
\hline & & & 1 & 2 & 3 & 4 & 5 & & \\
\hline & & & \multicolumn{2}{|c|}{ Menzel } & \multirow{2}{*}{$\begin{array}{l}\text { Very } \\
\mathrm{A}: \mathrm{B}\end{array}$} & \multicolumn{2}{|c|}{ Menzel } & & \\
\hline & & & W.C.T. & $A: B$ & & $A: B$ & W.C.T & & \\
\hline 1924 & & & & & & & & & \\
\hline Aug. $\begin{array}{r}6 \\
14\end{array}$ & 33.5 & 41.7 & -1 & +12 & 14 & 12 & 2 & 8 & Syrtis Major. \\
\hline & 30.5 & 41.3 & +9 & +10 & 13 & 11 & 16 & 12 & Mare Sirenum. \\
\hline & 31.1 & 38.6 & +4 & -5 & 8 & 7 & 13 & 6 & Do. \\
\hline 21 & 32.5 & 40.7 & +3 & +6 & 12 & 10 & 6 & 7 & \\
\hline & 34.9 & 39.1 & -5 & -3 & 6 & 8 & -7 & 0 & Bright region north of Mare Siro \\
\hline $\begin{array}{l}23 \\
25\end{array}$ & $\begin{array}{l}32.8 \\
33.7\end{array}$ & $\begin{array}{l}36.6 \\
38.3\end{array}$ & $\begin{array}{l}+2 \\
-7\end{array}$ & $\begin{array}{l}-20 \\
-8\end{array}$ & $\begin{array}{l}3 \\
7\end{array}$ & $\begin{array}{l}4 \\
6\end{array}$ & $\begin{array}{l}+4 \\
+2\end{array}$ & $\begin{array}{l}-1 \\
-1\end{array}$ & $\begin{array}{l}\text { Do. } \\
\text { Bright region north of Beak of }\end{array}$ \\
\hline & 31.2 & & +4 & $+55 ?$ & 32 & 24 & 12 & & $\begin{array}{l}\text { Sirens. } \\
\text { Solis Lacus: poor seeing. }\end{array}$ \\
\hline Sept. 11 & 30.8 & 47.8 & +1 & +45 & 26 & 20 & 15 & 22 & Syrtis Major. \\
\hline 13 & 29.6 & 39.3 & +6 & -2 & 10 & 8 & 22 & 9 & Do. \\
\hline $\begin{array}{l}13 \\
14\end{array}$ & $\begin{array}{l}25.1 \\
29.3\end{array}$ & $\begin{array}{l}55.8 ? \\
46.4\end{array}$ & $\begin{array}{r}+22 \\
+6\end{array}$ & +40 & $\begin{array}{l}42 \\
22\end{array}$ & $\begin{array}{l}32 \\
18\end{array}$ & 25 & $\begin{array}{l}32 \\
22\end{array}$ & $\begin{array}{l}\text { Syrtis Major. 18.4-foot focus. } \\
\text { Mare Cimmerium. }\end{array}$ \\
\hline
\end{tabular}

EXPLANATION OF TABLE I

MARs.-Comparison of temperatures on the apparent center of the disk as calculated (1) by the fourthpower law of black body radiation and the observed Martian water-cell transmissions W. C. Ts., (2) by the law of spectral radiation and the ratio of the Martian spectral radiation components $A: B$, (3) by plotting Very's observed lunar temperatures against the observed lunar spectral radiation components A : B and extrapolating to the observed ratios of the Martian components (4) by calculating the lunar temperatures (Menzel) from the lunar water-cell transmissions, using the fourth-power law, plotting these temperatures against the observed lunar spectral components $\mathrm{A}: \mathrm{B}$, and extrapolating to the observed ratios of the Martian spectral radiation components, and (5) by plotting the lunar temperatures (which were obtained by calculation from the lunar water-cell transmissions, using the fourth-power law) against the observed lunar water-cell transmissions and extrapolating to the observed Martian watercell transmissions. Observations at the 53.3-foot focus; receiver $0.23 \mathrm{~mm}$ in diameter. 


\section{PLANETARY TEMPERATURES DERIVED FROM THE IAW OF SPECTRAL RADIATION}

The data obtained with the water cell give us no information concerning the spectral energy distribution of the planetary radiation at 8 to $15 \mu$. Hence, in addition to the water cell used in previous measurements of planetary radiation, in the measurements of 1924 a new method was employed. This consisted in separating the planetary radiation of wave lengths 8 to $15 \mu$ into two components by means of transmission screens of glass and fluorite, giving spectral radiation components (A and B) of wave lengths 8 to $12.5 \mu$ and 12.5 to $15 \mu$. This involves the laws of spectral radiation, and the errors in the transmission coefficients of the air and of the fluorite screen have a direct effect upon the calculated temperatures. Moreover, the ratios of the spectral components, $\mathrm{A}: \mathrm{B}$, vary but slowly with the temperature which reduces the accuracy of the temperature estimates.

However, this method is important in testing selective emission. For example, it shows that of the total planetary radiation of wave lengths 8 to $15 \mu$ emitted by Venus over 62 per cent lies in the region of 8 to $12.5 \mu$, and hence that this method, as well as the method of calculation of the temperature of the planet by the fourth-power law, is questionable.

The temperatures derived from the spectral energy distribution of a black body may require correction for selective emission which would affect the ratio, $\mathrm{A}: \mathrm{B}$, of the spectral radiation components. If the radiating surface is composed of vegetable matter (cellulose) which has practically no selective reflection, the radiation emitted would be somewhat like that of a gray body. Hence, the temperatures assigned to the observed ratios would be close to the true values.

If the average emissivity in the spectral region of 8 to $12.5 \mu$ is higher than that of the spectral component at 12.5 to $15 \mu$, then the observed ratios of $\mathrm{A}: \mathrm{B}$ would be too large, and the true temperatures would be lower than the values read from the calibration curve. From our knowledge of the emissive and reflective properties of substances there are no indications that the observed temperatures would have to be lowered.

If the surface of Mars is composed of material similar to that on this earth-namely, silicates, carbonates, sulphates (quartz, mica, feldspar, granite, selenite, etc.), which have a high selective reflection ${ }^{17}$ in the spectral region of 8 to $12.5 \mu$-then the emissivity would be decreased in this region relative to the region of 12.5 to $15 \mu$. Consequently, the observed ratios of $\mathrm{A}: \mathrm{B}$ would be too low, and the temperatures as read from the calibration curve $A$, Figure 1, would have to be increased.

${ }^{17}$ See Figure 90 on p. 113 of Publ. No. 65, Carnegie Inst. of Washington; 1906. 
It is difficult to make this correction because the fluorite screen does not have a sharp cut-off at $12.5 \mu$. However, from general laboratory experience, a correction of $10^{\circ} \mathrm{C}$. is a conservative estimate. In other words, the temperatures derived from the spectral radiation components are minimum values which are to be increased but slightly if the surface is vegetation and by 10 to $15^{\circ} \mathrm{C}$. if the surface is similar to that of the earth.

One of the difficulties involved in these calculations is the lack of exact information on transmission of the earth's atmosphere in the spectral region extending from 8 to $15 \mu$. The data used in these calculations (including the absorption by ozone and $\mathrm{CO}_{2}$ ) are due to Fowle. ${ }^{18}$

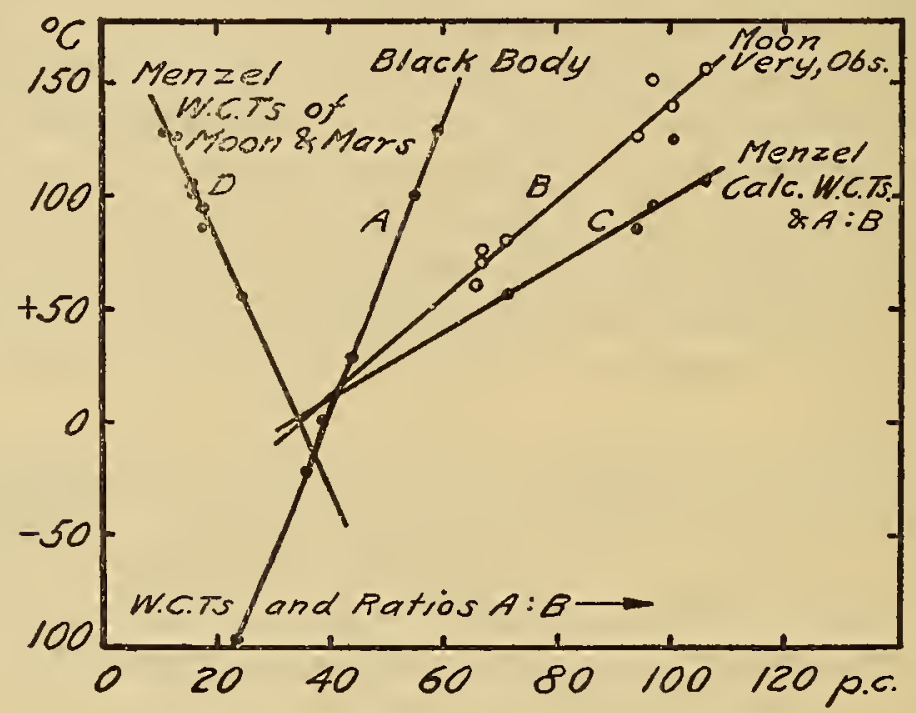

FIG. 1.-Temperature calibration curves

The procedure followed in these calculations consisted in plotting the spectral energy curve of a black body at, say, $0^{\circ} \mathrm{C}$. and multiplying the ordinates by the spectral transmission of the air. This gives a new curve extending from 8 to $15 \mu$, with an indentation at $10.5 \mu$. The ordinates of this curve, which is supposed to be similar to the incoming planetary radiation, were then multiplied by the transmission factors (corrected for reflection which is very small at 9 to $12 \mu$ ) of the fluorite screen,,$^{19}$ and the resultant curves were integrated. The areas under these two curves represent the planetary radiation components extending from 8 to $12.5 \mu$ and 12.5 to $15 \mu$, respectively. The calculated ratios of these two areas $A: B$ vary from 36 per cent at $-23^{\circ} \mathrm{C}$. to 60 per cent at $127^{\circ} \mathrm{C}$.

In practice, the planetary temperatures are obtained by comparing the observed ratios with the calculated values, plotted in curve $A$ of Figure 1. Referring to Table 1, in which are given the observed

18 Fowle, Smithsonian Physical Tables, 7 th ed.

10 Coblentz, Publ. No. 97, p. 45, Carnegie Inst. of Washington; 1908. 
ratios of the spectral components, it may be noticed in column 5 that the corresponding temperatures range from $-20^{\circ} \mathrm{C}$. for the bright regions to $35^{\circ} \mathrm{C}$. or even higher for the dark regions.

The mean value of the ratios $\mathrm{A}: \mathrm{B}$ of all the measurements made on the illuminated center of the disk, not taking into consideration the fact that the bright areas are at a much lower temperature than the dark areas, is 41.5 per cent, the corresponding temperature being $12^{\circ}$ C. or $54^{\circ} \mathrm{F}$.

This method presupposes a uniform temperature distribution, and hence requires a receiver which intercepts only a small portion of the image of the planetary disk. Using a large receiver or a small planetary disk (see data obtained at the 18-foot focus) gives anomalous results, which seem attributable to the variation in temperature of the surface from the Equator to the poles of the planet.

It would be desirable to have a screen which has a sharp cut-off in the infra-red spectrum. The transmission of the fluorite screen does not terminate as abruptly in the region of $12 \mu$ as does the quartz screen at $4.1 \mu$.

A weakness in this method is owing to the fact that the spectral range of the planetary radiation is narrow, and the spectral transmissions of the atmosphere and of the fluorite screen at 10 to $11 \mu$ are not known with sufficient accuracy to determine the temperatures to better than $10^{\circ} \mathrm{C}$. However, this is an independent method for obtaining temperature levels.

Ordinarily it would be considered sufficiently close to have determined the temperature level to within $10^{\circ} \mathrm{C}$. However, in the present problem the temperature estimates range about $0^{\circ} \mathrm{C}$., and the question at issue is whether or not the average of these estimates places the value somewhat above $0^{\circ} \mathrm{C}$., for the possibility of vegetation on Mars depends partly upon this temperature estimate. While the results obtained by this method give a wider range of temperatures than the other methods (see Table 1), its usefulness in supplementing the other methods seems evident.

\section{PLANETARY TEMPERATURES DERIVED FROM A COMPARISON WITH THE MOON}

The temperature of the irradiated surface of the moon is generally conceded to be much higher than that of the earth. It was therefore instructive to make comparative measurements as a check upon the two preceding methods of estimating temperatures on Mars. In this method of temperature calibration in our preliminary publications use was made of lunar temperatures calculated by Dietzius ${ }^{20}$ and those observed by Very. ${ }^{21}$

\footnotetext{
${ }^{20}$ Dietzius, Sitzber, Akad. Wiss. Wien., 132, p. 193; 1924.
}

11 Very, Astrophys. Jour., 8, pp. 199 and 265; 1898. 
Dietzius made his calculations on the assumption that the moon's visual albedo is $\alpha=0.13$ instead of the commonly accepted value $\alpha=0.073$. For the coefficient of total radiation of a black body he used $\sigma=1.28 \times 10^{-12}$ instead of the more nearly correct value $\sigma=1.37 \times 10^{-12} \mathrm{~g}$ cal. $\mathrm{cm}^{-2} \mathrm{sec}^{-1}$. For the emissivity $(1-\alpha)$ of long-wave-length infra-red radiation, with which we are especially concerned in lunar radiation, he used the value $0.87\left(\alpha=\alpha_{1}=0.13\right)$ whereas most of the minerals that probably form the surface of the moon, especially sand, mica, aluminum silicates, etc., have a high selective reflection ( $\alpha_{1}=0.20$ to 0.40 or even higher) in the spectral region ${ }^{22}$ of 7 to $12 \mu$. This would reduce the emissivity and raise the temperature. Fortunately, the mathematical formula used by Dietzius is of such a type that the errors which result from using the wrong values of $\alpha=\alpha_{1}$ and $\sigma$ practically cancel each other. Making these corrections would raise his calculated temperatures about $5^{\circ}$ C. Although these calculated values were considered in our preliminary papers on this subject they are not used in the present summary.

Instead of employing Dietzius's theoretical calculations in the present paper use is made of the lunar temperatures calculated by Menzel, ${ }^{23}$ from the observed lunar water-cell transmissions and the fourth-power law, using. Russell's formula. These temperatures are given in column 5 of Table 2 .

\section{TaBLe 2.-Moon}

JObserved spectral components of planetary radiation A:B (8 to $12.5 \mu$ and 12.5 to $15 \mu$ ) and (1) the corresponding temperatures from Very's observations; also the observed water-cell transmission (W. C. T.), and (2) the corresponding tempcratures calculated by Menzel, from Russell's formula, and (3) temperatures calculated by Dietzius]

\begin{tabular}{|c|c|c|c|c|c|}
\hline \multirow[b]{2}{*}{ Date } & \multirow[b]{2}{*}{$\begin{array}{l}\text { Ratio, } \\
\text { A : B }\end{array}$} & \multirow[b]{2}{*}{ W. C. T. } & \multicolumn{3}{|c|}{ Temperatures, ${ }^{\circ} \mathrm{C}$., from- } \\
\hline & & & $\mathrm{A}: \mathrm{B}$ & พ. $\stackrel{2}{\mathrm{C} . \mathrm{T} .}$ & $\stackrel{3}{\text { Dietzius }}$ \\
\hline 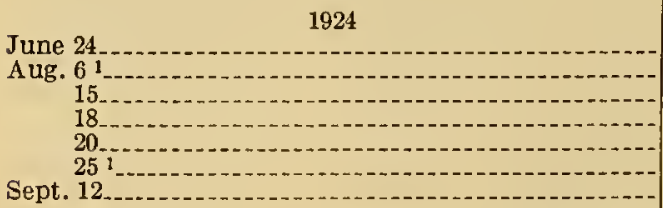 & $\begin{array}{r}100 \\
67 \\
71 \\
97 \\
106 \\
66 \\
94\end{array}$ & $\begin{array}{r}\text { Per cent } \\
12.6 \\
10.1 \\
24.1 \\
17.1 \\
15.5 \\
15.8 \\
17.4\end{array}$ & $\begin{array}{r}140 \\
70 \\
80 \\
150 \\
155 \\
60 \\
125\end{array}$ & $\begin{array}{r}125 \\
127 \\
55 \\
95 \\
105 \\
100 \\
85\end{array}$ & $\begin{array}{r}115 \\
95 \\
35 \\
85 \\
110 \\
86 \\
81\end{array}$ \\
\hline
\end{tabular}

1 Poor series.

The lunar temperatures calculated by Menzel from the observed water-cell transmission (Table 2), using Russell's formula and the fourth-power law, are plotted (curve $C$, fig. 1) against the observed ratios $A: B$ of the lunar spectral radiation components, and the Martian temperatures are obtained by extrapolation to the observed

22 Coblentz, Publs. Nos. 65 and 97; Carnegie Institution of Washington; 1906 and 1908.

${ }^{23}$ Menzel, Astrophys. Jour., 58, p. 65; 1923. See also a forthcoming paper by Menzel, Coblentz, and Lampland, Astrophys. Jour.; 1925. 
ratios A:B of the Martian spectral components. The Martian temperatures may be obtained also by plotting (curve $D$, fig. 1) the calculated lunar temperatures against the lunar water-cell dimensions (columns 3 and 5 of Table 2) and then extrapolating to the observed Martian water-cell transmissions.

Another method of comparing Martian and lunar temperatures consists in plotting the observed lunar ratios A:B against Very's ${ }^{24}$ observed temperatures (columns 2 and 4 of Table 2) at different ages of the moon and extrapolating to the spectral radiation ratios A : B observed on Mars. The calibration curve $B$ of Figure 1 obtained from Very's data is steeper than the one calculated from the water-cell transmissions of lunar radiation but less so than that calculated by the method which involves the spectral radiation law of a black body.

This gives a third method of estimating planetary temperatures. It yields three sets of values, which are given in columns 6,7 , and 8 of Table 1. The average values are in good agreement with those obtained by the other methods. The values calculated from the radiation laws and given in columns $4,5,7$, and 8 should be increased by $10^{\circ} \mathrm{C}$. to reduce them to true temperatures.

\section{PLANETARY TEMPERATURES INFERRED FROM COMPARISONS WITH THE EARTH}

It is important to notice that our measurements are on the radiation emitted by the solid surface of Mars, and that the temperature estimates pertain to the solid surface. On the other hand, the recorded temperatures of the earth are of the overlying atmosphere, and hence they may be misleading in making comparisons, because the temperature of the irradiated solid surface, especially if it is composed of loose sand or dust, is usually much higher than that of the closely overlying air. The light-colored surface of Mars is no doubt Saharan-dry and dusty. If the dark-colored areas are vegetation, then the fact that the observed temperatures are higher than those of the adjoining light-colored areas can be accounted for on the assumption that at least part of this vegetation grows in tussocks.

The earth reflects about 45 per cent (absorbs and scatters about 55 per cent) of the incident solar radiation. Under these conditions the air close to the surface has a mean temperature of about $15^{\circ} \mathrm{C}$., while the temperature of the dry solid surface rises to $40^{\circ} \mathrm{C}$., or even higher. The intensity of the solar radiation incident upon the outer atmosphere of Mars near perihelion is close to one-half that incident upon the earth, but the surface of Mars reflects only about 15 per cent. Hence, in spite of the fact that the intensity upon its outer surface is only 51 per cent as much as falls upon the earth, it absorbs

24 Very, Astrophys. Jour., 8, pp. 199 and 265; 1898. 
and effectively utilizes about 85 per cent as much of the incident solar energy as does the earth per unit area with the sun in the zenith.

It is important to notice that the albedo of 0.15 for Mars is a mean value for the whole surface (including the white polar regions), which value, no doubt, varies with the seasons. Some of our measurements show that certain dark areas reflected only 85 to 90 per cent as much as the adjoining bright regions, producing an observed difference in temperature of 10 to $20^{\circ} \mathrm{C}$., the calculated difference being 10 to $15^{\circ} \mathrm{C}$.

The maximum of solar radiation is in the violet, wnuch is more depleted in passing through the earth's atmosphere than through the Martian atmosphere. Hence, the insolation upon the solid surface of Mars is more effective in raising the temperature than on the surface of the earth.

As already stated, at summer solstice the air temperature in this latitude is up to $22^{\circ} \mathrm{C}$., while the dry solid surface, in which we are especially interested has a temperature of $27^{\circ} \mathrm{C}$. $\left(300^{\circ} \mathrm{K}\right.$.) or even higher. At opposition, August 21, the insolation on Mars (assuming an albedo of 0.15 ) was about 85 per cent as intense as upon the earth. The temperature would be proportional to the fourth root of this value $(0.96 \times 300)=288^{\circ} \mathrm{K}$. or $15^{\circ} \mathrm{C}$. If the insolation is only 80 per cent as intense, then the temperature of the solid surface of Mars would be $11^{\circ} \mathrm{C}$. These values are in agreement with the observations. A surface temperature of $40^{\circ} \mathrm{C}$. on the earth would be equivalent to $20^{\circ} \mathrm{C}$. on the apparent center of the disk of Mars at opposition.

It is well known that during the summer the total daily insolation at the terrestrial, also Martian, pole is greater than on the Equator. This is owing to the fact that during the summer the rapidly increasing length of the day toward the pole more than compensates for the decreasing angle at which the solar rays strike the earth. For example, at summer solstice, at $0^{\circ}, 20^{\circ}$, and at $90^{\circ}$ north latitude, the proportional amounts are $0.88,1.0$, and 1.2 , respectively. Or, translated into energy incident upon a horizontal surface at the top of the earth's atmosphere, the total insolation is, respectively, about 800,950 , and $1,100 \mathrm{~g}$ cal. per $\mathrm{cm}^{2}$ per day..$^{25}$

The most of our measurements were made when the apparent center of the disk was at about $20^{\circ}$ south latitude. Hence, assuming an albedo of 0.154 , the insolation on Mars at summer solstice (October 5) at $20^{\circ}$ south latitude and at the South Pole was, respectively, about 450 and $500 \mathrm{~g}$ cal. per $\mathrm{cm}^{2}$ per day. The corresponding values absorbed by the earth at summer solstice (June 21) would be about 550 and $600 \mathrm{~g}$ cal. per $\mathrm{cm}^{2}$ per day. This condition of a higher insolation in the terrestrial polar region than on the Equator at the same time continues for about 12 weeks, at the time of the

${ }^{25}$ Calculated from data given in Smithsonian Pbys. Tables and Hann's Elimatologie. 
summer solstice. On Mars the time would be about twice as long or, taking into consideration that we may not have been setting our thermocouple receiver exactly upon the South Pole, then our measurements pertain to a region that was exposed continuously for 125 to 160 days to solar radiation as intense as that at the Martian equator.

The temperature rise in our arctic regions during the summer is well known. The reason the temperature does not rise higher is owing to the large amount of energy expended in melting the wide expanses of snow and owing to the depletion of the incident solar radiation in passing through the large mass of air and atmospheric water vapor. On Mars conditions are different. There is but little water, either in the liquid or solid state, and the atmosphere is no doubt, small in comparison with the earth. The temperature of the solid surface would, therefore, be expected to rise almost as high as that of the earth. In fact, with much clearer skies and with less air convection in some of the darker places on Mars, especially in the temperate and the frigid zones where the insolation is so prolonged, the temperature should be considerably higher than observed on the surface of the earth, There is, therefore, no need of surprise at the results recorded in this paper. Perhaps the surprise should be in the fact that the temperatures are so low, especially when we take into consideration the probable presence of vegetation similar to our tussock grasses, mosses, and lichens, which have a high absorptivity of solar radiation, but which have a low thermal conductivity. This will produce a high temperature on the upper surface of the vegetation, which is the region upon which our measurements are made. It is the radiation from the highly heated isolated regions scattered here and there over the surface that is transmitted through our atmosphere and measured by the thermocouple. The smallest receiver at the 53 -foot focus intercepted about 500 miles of circum. ference, or an area of about 190,000 square miles of surface at the center of the disk.

\section{COMPARISON OF TEMPERATURE ESTIMATES}

In the foregoing part of this paper four methods were outlined for obtaining an estimate of the temperature of the irradiated surface of Mars. The most complete measurements were obtained along the apparent center of the disk. As already mentioned, at opposition the thermocouple receivers, which were $0.23 \mathrm{~mm}$ in diameter, covered less than one-eighth of the planetary disk image when used at the 53.3-foot focus of the 40 -inch reflector. Hence, the effect of change in temperature with latitude may be neglected for the present. Moreover, since the bright areas are at a lower temperature than the dark areas it is relevant to mention that usually the areas measured, whether the small south polar cap or the bright and dark regions on 
the Equator, were the same size as or larger than the receiver. The ratios of the spectral components $(\mathrm{A}: \mathrm{B})$ of the planetary radiation of wave lengths 8 to $12.5 \mu$ and 12.5 to $15 \mu$ range from 37 per cent for the bright areas to 50 per cent for the adjacent dark areas on the equatorial belt. Many of the ratios range about the value of 42 per cent.

The average of 10 sets of ratios of spectral radiation components obtained on as many nights from August 14 to September 12 is 41.5 per cent. This represents a temperature of $8^{\circ} \mathrm{C}$. by method (2), which utilizes the law of spectral radiation, and $12^{\circ} \mathrm{C}$. (average of the calibration from Very's experimental value, $16^{\circ} \mathrm{C}$., and Menzel's calculated values, 13 and $9^{\circ} \mathrm{C}$., respectively) by method (3), which is a direct calibration against the moon. From the water-cell transmissions and method (1), using the fourth-power law of total radiation, the corresponding temperature is $5^{\circ} \mathrm{C}$. (true temperature $15^{\circ} \mathrm{C}$ ). This method is probably better adapted to calculating the average temperature of the whole disk.

From the foregoing it is evident that these various methods are in agreement in showing that the noonday temperature of the equatorial region of Mars at perihelion is of the order of 10 to $20^{\circ}$ C. This is in agreement with method (4), which involves a comparison with temperature conditions on this earth.

These methods indicate temperatures of -10 to $5^{\circ} \mathrm{C}$. in the bright regions and 10 to $20^{\circ} \mathrm{C}$. or even higher in the dark regions. The temperature values which are below $0^{\circ} \mathrm{C}$. are inconsistent with the visual observations which show that snow is never seen on the Equator at Martian noon. ${ }^{26}$ While this may be owing to the wellknown fact that snow evaporates at a temperature below $0^{\circ} \mathrm{C}$., the temperature data as a whole are consistent with other phenomena observed on Mars, showing that the temperature rises above $0^{\circ} \mathrm{C}$. This is a very important deduction for the simple reason that prior to our measurements of 1922, and especially those of the past summer, the idea seemed to prevail that it is physically impossible for the temperature of Mars to rise above $0^{\circ} \mathrm{C}$.

The temperature data are assembled in Tables 2 and 3 . The values calculated from the black body radiation laws are to be increased by about $10^{\circ} \mathrm{C}$. in order to reduce them to true temperatures.

${ }^{26}$ See summary by Pickering, Pop. Astron., 30, p. 410; 1922. 
TABLE 3.-Temperatures of isolated areas on Mars

[Water-cell transmissions (W.C.T.) in per cent of the total radiation emanating from isolated areas and the corresponding black-body temperatures ealculated by the fourth-power law. The true temperatures would be about $10^{\circ}$ bigher. The temperatures marked with a $\left(^{*}\right)$ were taken from the curve of average values]

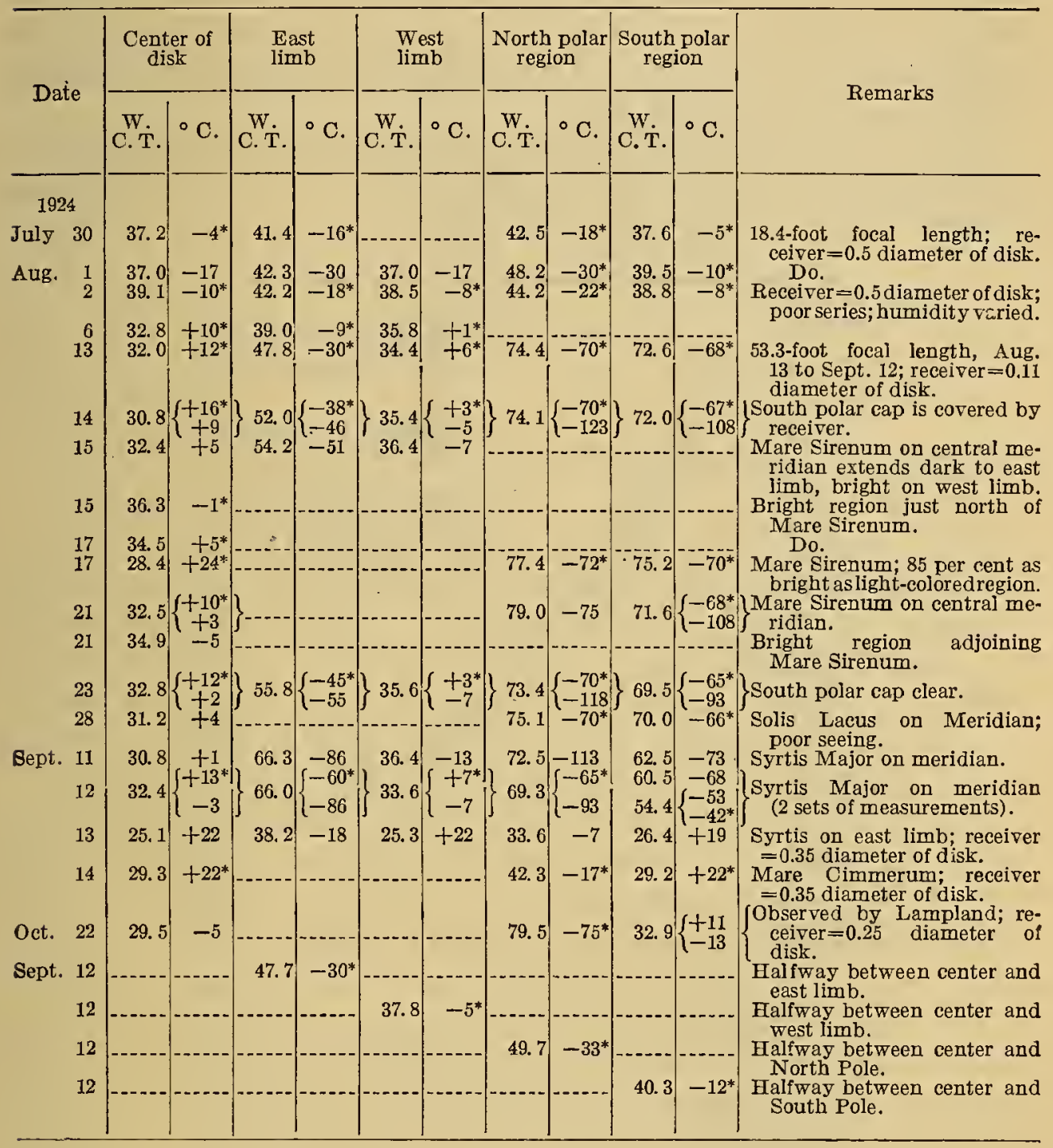

In Figure 2 the circles ( $\bigcirc \bigcirc)$ represent the Martian temperatures derived from the observed ratios of the spectral radiation components, $A: B$, using Very's lunar temperatures and the corresponding Martian water-cell transmissions (columns 2 and 6 of Table 1). In this same illustration the dots (...) represent the temperatures calculated from the observed Martian water-cell transmissions, and the fourth-power law of total radiation (columns 2 and 4 of Table 1, also data in Table 3), $10^{\circ} \mathrm{C}$., having been added to the calculated values to reduce them to true temperatures. The data superpose very well considering the difficulties involved in estimating planetary temperatures. As a check on our work, in the preliminary communications it was assumed 
that when the water-cell transmission of the radiation from Mars was 75 per cent (the same as the sky) the temperature of the Martian surface was down to that of the earth's stratosphere; that is, about $-70^{\circ} \mathrm{C}$. From the agreement in these two sets of data it appears that this assumption of $-70^{\circ} \mathrm{C}$. is not in serious disagreement with the calculated values which are based upon assumptions regarding the albedo of the polar regions.

In this same illustration is shown the relative size of the planetary image and of the thermocouple receiver; also of the method of making settings on the bright and the dark areas.

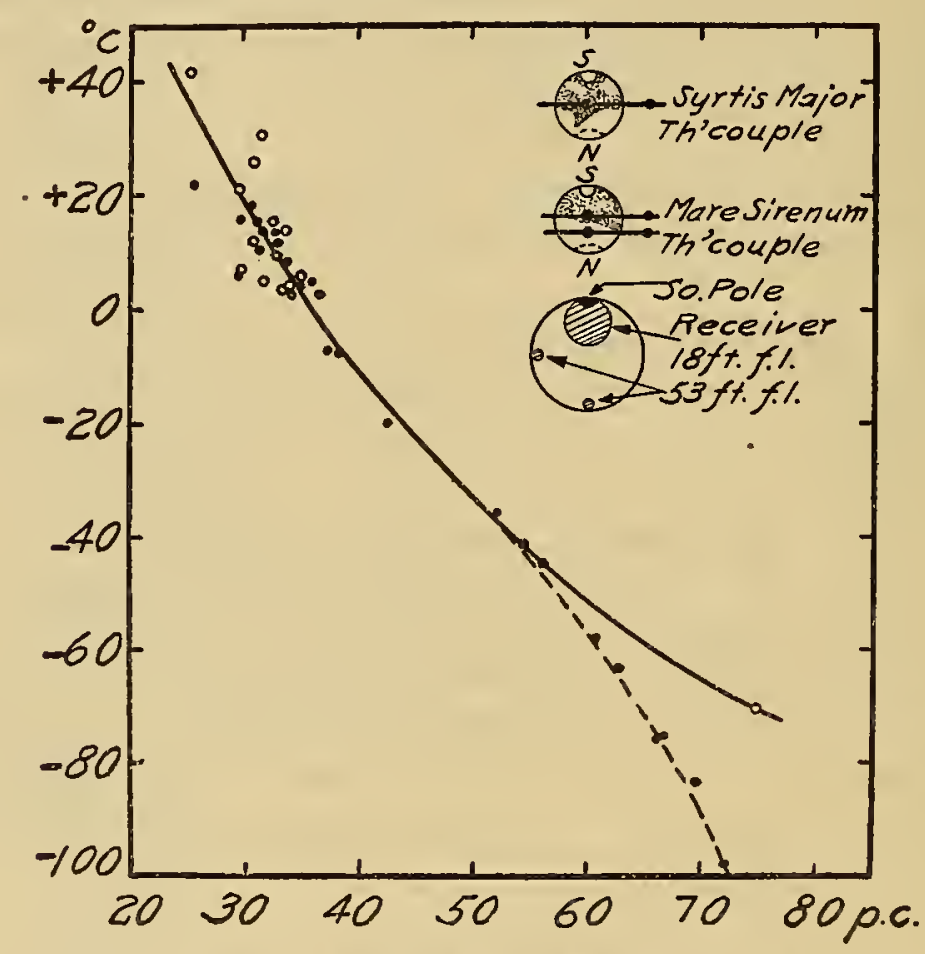

FIG. 2.-Observed water-cell transmissions of the radiation from Mars and the corresponding temperatures

The circles represent the Martian temperatures obtained by extrapolation from Very's observed lunar temperatures. The dots are the temperatures calculated (by Menzel) from the fourth-power law of total radiation, and corrected by $10^{\circ} \mathrm{C}$. to reduce them to true temperatuies.

\section{CLIMATIC CONDITIONS ON MARS}

In a recent discussion of climatic conditions on Mars, inferred from phenomena generally observed on the planet, Pickering ${ }^{27}$ estimated the mean annual temperature at $20^{\circ} \mathrm{F}$. $\left(-7^{\circ}\right.$ C. $)$ as compared with the mean annual temperature of the earth of $59^{\circ} \mathrm{F}$. $\left(15^{\circ} \mathrm{C}.\right)$. At night the Martian temperature is below $32^{\circ} \mathrm{F} .\left(0^{\circ} \mathrm{C}.\right)$, and at noon it is, perhaps, 60 to $70^{\circ} \mathrm{F}$. ( $\left(15\right.$ to $20^{\circ} \mathrm{C}$.). These figures, which are singularly close to our observed values, are arrived at from

\footnotetext{
27 Pickering, Pop. Astron., 30, p. 410; 1922.
} 
the appearance of snow and frost during the course of the Martian day, and from the fact that snow is never seen on the Equator at Martian noon.

\section{AVERAGE TEMPERATURE OF THE WHOLE SURFACE OF MARS}

From the water-cell transmissions of the radiation from the whole disk of Mars, obtained on June 24 and 25, the calculated temperatures by method (1) using the water-cell transmissions, are $237^{\circ} \mathrm{K}$. and $242^{\circ} \mathrm{K}$., respectively, for the thermocouple having a rock-salt window and $250^{\circ} \mathrm{K}$. (June 25) when the window was of fluorite. This is in good agreement with the measurements of Pettit and Nicholson, ${ }^{28}$ who obtained a temperature of $260^{\circ} \mathrm{K}$. for the integrated disk. It represents an average temperature of $-30^{\circ} \mathrm{C}$. for the whole disk, which is a different thing from our measurements on isolated areas.

\section{RADIATION FROM AND TEMPERATURES OF SELECTED REGIONS}

Under this caption it will be shown that, when observed on the central meridian, hence under the same illumination and air mass, the dark areas on Mars emit a greater amount of planetary radiation and are, no doubt, hotter than the bright areas. From this it seems evident that it would be futile to attempt a zonal radiometric survey of the whole surface unless a complete specification can be made of the conditions under which the observations are made.

(a) Bright and Dark Equatorial Regions.-Whether the measurements were made with a receiver having 0.4 or 0.11 of the diameter of the image of the planetary disk, the data are in agreement in showing a lower water-cell transmission, and hence a higher planetary radiation, from the dark regions than from the bright regions.

An exceptionally good opportunity for testing the difference in the planetary radiation emanating from equally irradiated bright and adjoining dark regions on the apparent center of the disk was obtained on August 15 and 17 . The particular parts on the meridian were the dark area, known as Mare Sirenum, and the bright region directly to the north. The measurements of August 21 were made nearer to the point of this dark area, known as the "Beak of the Sirens." (See sketch in fig. 2.)

In all cases the dark regions have a lower water-cell transmission than the bright areas. The difference in temperature between the bright and the dark regions is appreciable, amounting to $10^{\circ} \mathrm{C}$. or, perhaps, even greater (see Tables 1 and 3).

(b) East And West Limbs.-All the measurements, with the large and the small receivers, are in agreement in showing that the east

${ }_{28}$ Pettit and Nicholson, Pop. Astron., 32, p. 601; 1924. 
limb, which is the side just turning into the sunlight, has a higher water-cell transmission than the west limb. In other words, the sunrise side of the planet is cooler than the side under the afternoon sun. Both limbs of the planet are really hotter than indicated, but owing to the larger air mass than on the central meridian the intensity of the outgoing planetary radiation is reduced.

During the latter part of July and the first part of August there was an appreciable phase, as a result of which the eastern limb of the planet was already irradiated and heated for an hour or more before rotating into view. Hence, as this heated portion rotated into view, the morning side was hotter than it would have been if there had been no phase. Nevertheless, it was at a lower temperature than the west limb. The measurements on August 23 were made when the equatorial zone north of Mare Sirenum was bright entirely across the disk. Hence, the measurements on this date show to the best advantage the difference in temperature between the east and west limbs of the planet.

During the first part of August usually no measurements were made until the large dark region, known as Syrtis Major (see sketch in fig. 2) had passed from view. However, on August 6, the Syrtis was on the center of the disk, and although the east and west limbs appeared equally illuminated the latter was the warmer.

The observations of August 15 are especially interesting, because a bright region was on the west limb and a dark region was on the east limb. Nevertheless, the west limb was the warmer.

The direct galvanometer deflections observed on the east limb are appreciably lower than on the west limb. While this is a further verification of a difference in temperature, as emphasized in our complete paper on this subject, we have avoided interpreting the direct deflections, preferring ratios of intensities which do not involve galvanometer sensitivity, air mass, etc.

In a recent communication on this subject Pettit and Nicholson ${ }^{29}$ state that their drift curves, taken across the disk of Mars, do not show a displacement of the noon point, and hence are in disagreement with our measurements which show a higher temperature in the Martian afternoon than in the forenoon. It is to be noted, however, that they used a receiver which intercepted one-fourth of the diameter of the disk as compared with one-eighth of the disk in our measurements.

Our measurements are in agreement, at least qualitatively, with what one would expect from a consideration of the radiative properties of a rapidly rotating planet exposed to the sun, viz, on the Equator a daily cycle of approximately 12 hours accumulating heat and 24 hours losing heat. If the excess which is accumulated during

${ }^{20}$ Pettit and Nicholson, Pop. Astron., 32, p. 601; 1924. 
the day is not entirely lost during the remaining part of the cycle, there is a gradual rise in temperature, as we have observed in the south polar region. On the Equator, where the insolation was fairly constant during the summer, the temperature remained fairly constant.

It.is difficult to see how a surface which is just rotating from night into the morning sun can have the same temperature as a similar region at sunset after it has been exposed continuously for 12 hours or more to the sun. This would involve the formation of a peculiar type of fog or cloud which the visual observations do not seem to record.

(c) North and South Polar Regions.-The measurements of this year have verified the observations of 1922 , showing that the north polar region is cooler than the south polar region.

Using the 53.3-foot focus and the smallest receivers, it was possible to practically isolate the south polar cap. Early in July the watercell transmissions were practically that ( 75.5 per cent) of the direct solar radiation, showing that no planetary radiation is emitted from the polar caps. This is especially true of the north polar cap, which shows a systematically lower water-cell transmission than the south polar cap (Table 3). After the snow had practically disappeared from the south polar cap there was a rapid rise in temperature with advance in summer, which is similar to conditions that occur in Alaska and Siberia. From this it is evident that the subject of planetary radiometry, especially of Mars, has advanced to the stage where a systematic study of this planet will make it possible to establish a complete table of climatological conditions extending throughout the Martian year.

While the measurements were in progress it was winter in the north polar regions. Under these conditions the temperature of the irradiated north polar region was down to $-70^{\circ} \mathrm{C}$. or, perhaps, even lower, and continued at this temperature during most of the season. Sinilar temperatures occur in our arctic regions during the winter.

When these measurements were in progress it was early summer on the Southern Hemisphere and the temperature of the south polar region, as observed through the overhanging atmospheric mantle of mist or, perhaps, ice spicules, was $-60^{\circ} \mathrm{C}$. However, in view of the fact that it was the summer season, with melting snow and a receding polar cap, it is reasonable to assume that the temperature of the solid surface at the South Pole was up to $0^{\circ} \mathrm{C}$.

To the writer the apparent temperature of $-60^{\circ} \mathrm{C}$. as measured through the water cell during the early Martian summer in the south polar region, is not inconsistent with the common-sense interpretation of the visual observations (receding polar cap, melting ice), indicating a temperature up to $0^{\circ} \mathrm{C}$., but is a remarkable verification of the 
presence of an atmosphere containing a mantle of ice spicules or, perhaps, water vapor ("mist") which prevents the escape of planetary radiation from the solid surface. It is to be noted that our interpretation of planetary temperatures is based upon the radiation of wave lengths 8 to $15 \mu$ which emanates from the planet. Evidently this overhanging mantle is of considerable extent, and, perhaps, in the form of a thick mist or fog which is opaque to these wave lengths; for it is well known that the highly attenuated water vapor in our atmosphere is quite transparent to radiation of wave lengths 8 to $15 \mu$, whereas mist and fog prevent the transmission of infra-red rays of long wave length.

The measurements which were made at the same time, using a larger receiver (see diagrams in fig. 2) that intercepted the whole of the south frigid zone and part of the south temperate zone, indicated temperatures up to $10^{\circ} \mathrm{C}$.

The temperature of the south polar cap changed but slowly during July and August. However, in September the temperature began to rise rapidly, and by October the water-cell transmissions decreased to 30 per cent, or even lower, indicating a temperature of $6^{\circ} \mathrm{C}$. (true temperature about $15^{\circ}$ C.). This is extremely interesting in view of Reverend Phillips's ${ }^{30}$ recent paper on this subject, in which micrometric measurements are given showing that the melting of the snow was not very rapid during July, but that the cap diminished rapidly in size during August and September and became very small in November.

This rapid rise in temperature of the south polar region from $-60^{\circ}$ (the temperature of the isothermal layer of the polar canopy; $0^{\circ} \mathrm{C}$. if interpreted from the visual observations of the receding cap of melting ice) in July to $10^{\circ} \mathrm{C}$. or even higher at the Martian summer solstice is, perhaps, the most important and the most interesting result of this investigation. From the foregoing discussion of the prolonged insolation on the polar region such a temperature is to be expected.

In concluding this discussion, it is of interest to consider Wright's ${ }^{31}$ photographs of the surface of Mars as riewed through red glass and in contrast with the photographs made in blue light, which show the combined effect of the surface and the surrounding atmosphere. These photographs show regions on the Northern Hemisphere which are as bright as the south polar caps. This is to be expected in view of our temperature measurements, which show low temperatures and the possible formation of frost and deposits of snow "in these regions. If, as already mentioned, the dark areas contain vegetation in the form of tussocks scattered here and there over the

30 Phillips, Mo. Notices R. A. S., 85, p. 179; 1924.

at Wright, Publ. Astron. Soc. Pacilic, 36, p. 239; 1924. 
surface, and if there is a thin coating of snow or hoar frost on the surface of the ground, the brilliancy of the south polar region will be reduced relative to the bare desert areas along the equatorial belt, as indicated in the photographs.

\section{SEASONAL VARIATION OF TEMPERATURES ON MARS}

The gradual change in the water-cell transmissions and hence the surface temperatures with change in season on Mars is evident from a casual inspection of our tabulated data, but it is even more convincing to depict these data in the form of a graph as illustrated in Figure 3.

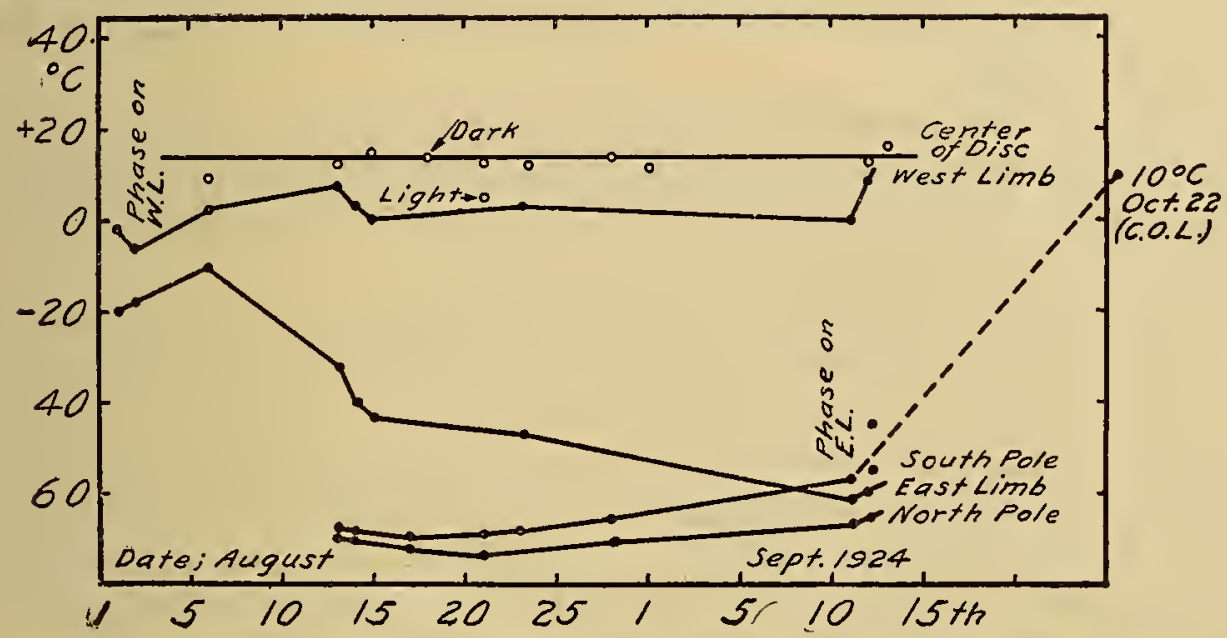

FIG. 3.-Seasonal variation in temperature on different regions of Mars

The measurements on the illuminated center of the disk are interesting in showing a fairly uniform temperature of about $14^{\circ} \mathrm{C}$. through- . out the six weeks from August 1 to September 14, when the series was concluded. Similarly, in the north polar region, where winter prevailed, the temperature departed but little from $-70^{\circ} \mathrm{C}$. if we except the minimum of $-75^{\circ} \mathrm{C}$. observed on August 21.

In contrast with the fairly uniform temperature conditions in the north polar region, the temperature of the south polar region was gradually rising from $-68^{\circ} \mathrm{C}$., observed on August 12 , to $-45^{\circ}$ C. ${ }^{32}$ observed on September 12, and $+10^{\circ}$ C. in November. This, of course, might be expected in view of the advance in the summer season on the Southern Hemisphere. After the summer solstice, on October 5, the water-cell transmissions decreased to 28 to 30 per cent, indicating a temperature of 10 to $15^{\circ} \mathrm{C}$.

On the west limb the observed temperature was -2 to $-8^{\circ} \mathrm{C}$. at the beginuing of August, when there was a small, dark phase. When

32 These values are too low owing to the presence of an overhanging canopy of mist or ice spicules as already explained. The receding ice cap would indicate a temperature close to $0^{\circ} \mathrm{C}$ 
there was practically no phase on the west limb the temperatures ranged from 0 to $6^{\circ} \mathrm{C}$.

Perhaps the most interesting measurements relate to the east limb, or sunrise side of the planet. During the first of August the east limb was irradiated for an hour or more before turning into view. Under these conditions the observed temperatures of the eastern limb range from -10 to $-20^{\circ}$ C. At opposition, August 22, when there was no dark phase, the temperature was down to $-45^{\circ} \mathrm{C}$. At the conclusion of the series at the 53.3-foot focus, on September 12, when the dark phase was barely perceptible on the east limb (illuminated surface 0.976 ), the temperature was $-60^{\circ} \mathrm{C}$. How much lower the temperature falls, and whether this very low temperature is owing to setting the receiver on the atmospheric envelope, remains to be determined.

From the low temperatures recorded at the poles and on the east limb where the measurements were made several hours after Martian sunrise, it appears that the temperature of the night side of Mars may fall below $-70^{\circ} \mathrm{C}$.

This study of the seasonal changes in temperature, especially of the southern hemisphere of Mars, was continued late into November by Mr. Lampland, using the same radiometric equipment and galvanometer employed by us during the preceding months. He reports that the water-cell transmissions of the radiation from the north polar region continued unchanged at 70 to 80 per cent, indicating a temperature of about $-70^{\circ} \mathrm{C}$., as was to be expected with winter on this hemisphere.

On the other hand, the water-cell transmissions of the radiation from the south polar region decreased from the high value observed in the early part of September to 30 per cent, or even lower, in November and December, indicating a temperature of 10 to $15^{\circ} \mathrm{C}$. or even higher. Granting that some ice still remained at the pole there would be a temperature gradient for which a correction should be made. On this basis the water-cell transmissions would be still lower and the temperature of the south polar region would be higher than indicated by these measurements. This is especially true if there is a suppression of the planetary radiation with increased air mass which would cause the observed temperatures to be lower than the true values. From this it appears that during the late Martian summer the temperature of the south temperate and the south frigid zones of Mars was up to $15^{\circ} \mathrm{C}$. or, perhaps, even higher.

In concluding this discussion, it is relevant to note that for the measurements made on different parts of the planet on successive nights the values seem to follow a sequence all higher or lower than those of the preceding or following night. This does not seem to depend upon the humidity, and an explanation thereof is not at 
hand. It would be interesting to study this effect with variation in the solar radiation intensity which is known to fluctuate appreciably.

This year was a sun-spot minimum, and from accounts already published the behavior of the polar cap seems consistent with the relationship between the melting of the polar caps and the cycle of solar activity, which question has been discussed by Antoniadi. ${ }^{33}$

According to the measurements of Phillips ${ }^{34}$ and the more extensive measurements of E. C. Slipher made at the Lowell Observatory, the rate of melting of the south polar cap was accelerated in August. This appears to coincide quite closely with the rise in temperature of the south polar cap, illustrated in Figure 3.

\section{CONCLUDING REMARKS AND SUMMARY}

In glancing over some of the literature on the subject it appears that opinions are well defined and easily arranged into two groups: (1) Those who by calculation arrived at the conclusion that the temperature of Mars does not rise above $0^{\circ} \mathrm{C}$., and (2) those who from visual observations of seasonal changes in color, variation in size of the polar caps, etc., concluded that the temperature rises above $0^{\circ} \mathrm{C}$.

It therefore seems proper to emphasize the fact that, during the past opposition, for the first time in history, physical measurements were made which give an indication that the temperature of the surface of Mars rises above the freezing point of water. As just stated, prior to our measurements of 1922, and especially those of 1924, the opinion prevailed that the temperature of Mars is far below freezing.

In reading the various books and papers on Mars-by Lowell, Pickering, Slipher, and others-it is surprising to find a close parallelism between the deductions of temperature conditions based on visual observations and the foregoing results based upon radiometric measurements. This is probably to be expected, although it was entirely unforeseen.

The foregoing radiometric measurements were made on 24 nights extending over a period of about 10 weeks, from July to September, 1924. The instruments used consisted of an ironclad Thomson galvanometer and vacuum thermocouples of bismuth and platinum, with windows of rock salt. The receivers, which were $0.23 \mathrm{~mm}$ in diameter, intercepted about one-eighth of the diameter of the disk of Mars at opposition.

By means of a series of transmission screens of water, quartz, glass, and fluorite the radiation emanating from Mars and other planets was separated into spectral components and the radiation intensities

3 Antoniadi Mo. Notices R. A. S. 76 p. 643; 1915.

4 Phillips Mo. Notices RoJ. Astr. Soc. 85 p. 179; 1724. 
determined in the spectral regions of 0.3 to $1.4 \mu, 1.4$ to $4.1 \mu, 4.1$ to $8 \mu, 8$ to $12.5 \mu$, and 12.5 to $15 \mu$.

In this manner it is possible to determine the shape of the spectralenergy curve of that part of the planetary radiation which is transmitted by our atmosphere and thereby form an estimate of the temperature of the effective radiating surface of the planet.

While the object of the present paper is to summarize the results of an investigation of methods of estimating planetary temperatures with especial reference to Mars, it is relevant to mention that radiometric measurements were made also on Venus, Jupiter, Saturn, Uranus, the moon, and on terrestrial sources; also that the results obtained verify our previous observations which showed that the planetary radiation emanating from Jupiter and from Saturn, and transmitted by our atmosphere, is very small, while the planetary radiation from Venus, Mars, and the moon is relatively very intense.

In the foregoing pages the radiometric measurements on the irradiated surface of Mars were reduced to temperatures by four independent methods of analysis, as follows:

(1) By calculation using the fourth-power law of black body radiation and the water-cell transmissions of the radiation from Mars;

(2) By means of the law of spectral radiation and the ratio of the observed spectral components $(\mathrm{A}: \mathrm{B})$ of the Martian planetary radiation, of wave lengths 8 to $12.5 \mu$ and 12.5 to $15 \mu$, as observed through the giass and the fluorite screens;

(3) By extrapolation from the lunar radiation measurements, (a) by plotting Very's observed lunar temperatures against the observed lunar spectral radiation components, $(b)$ by calculating the lunar temperatures from the lunar water-cell transmissions using the fourth-power law and plotting them against the observed lunar spectral radiation components, also (c) against the lunar water-cell transmissions (in all, three subsidiary methods); and

(4) By comparison with terrestrial climatic conditions.

These four independent methods give concordant results showing that the dark areas on the Equator have a higher temperature than the contiguous bright areas. The temperatures of the bright areas range from -10 to $+5^{\circ} \mathrm{C}$. The temperatures of the dark areas range from 10 to $20^{\circ} \mathrm{C}$, or even higher.

The arerage temperature of the apparent center of the disk, including the bright and the dark areas, was about $15^{\circ} \mathrm{C}$., rerifying the estimate of 10 to $20^{\circ} \mathrm{C}$., based upon the measurements of 1922 (B. S. Sci. Paper, No. 460, p. 553).

The temperature of the north polar region when winter prevailed remained fairly constant at $-70^{\circ} \mathrm{C}$. during the period corered by these observations. The temperature of the south polar cap, as viewed through the atmosphere and mist, remained fairly constant at about $0^{\circ} \mathrm{C}$. until September, when it rapidly increased to $10^{\circ} \mathrm{C}$, or perhaps higher. The true temperature wonld therefore be up to $20^{\circ} \mathrm{C}$., or perhaps even higher. 
The temperature of the east limb, or sunrise side, of the planet is lower than the west limb. At opposition, August 21, the temperature of the east limb was $-45^{\circ} \mathrm{C}$., and the west limb $0^{\circ}$ C.- - both places as viewed through the Martian atmosphere. The true temperature of the surface would be higher.

The average temperature of the whole disk in the latter part of June was $-30^{\circ} \mathrm{C}$. The temperature of the night side of Mars probably drops below $-70^{\circ} \mathrm{C}$.

The observed high surface temperatures may be accounted for on the assumption that these dark areas contain vegetation having the properties of the tuft-forming grasses of our high prairies and the tussock mosses and lichens of our dry tundras, which have a high absorptivity for solar radiation and a low thermal conductivity. The assumption of the presence of such a type of regetation is in harmony with the visual observations which show changes in the coloring of the dark areas with changes in the seasons, and it is in agreement with the low intensity of insolation on Mars. The radiometric observations indicate that during the summer season on Mars temperature conditions at noonday are not unlike the bright cool days on this earth, with temperatures ranging from 5 to $15^{\circ} \mathrm{C}$., or 40 to $60^{\circ} \mathrm{F}$.

Washington, April 28, 1925. 